\title{
ERECTOR SPINAE BLOCK WITH CATHETER PLACEMENT FOR RELIEF OF CHRONIC PAIN FROM SHOULDER DISARTICULATION
}

N. Aypa ${ }^{1}$, M. Beltran ${ }^{1}$, G. Ortiz Luis - Coํ.

Makati Medical Center, Department of Anaesthesiology, Makati City, Philippines

\section{OBJECTIVE AND BACKGROUND}

The erector spinae block provides analgesia of the anterior and posterior chest wall when performed at T5 with variable distribution reported between C7-T8 or T2-T9 dermatomes as indicated for neuropathic pain ${ }^{1}$, rib fractures ${ }^{2}$, and thoracic surgical procedures such as VATS 3 and breast surgery 4 . When performed at T7 or T8, it may provide analgesia for abdominal surgical procedures such as ventral hernia repair 5 and even relief of visceral abdominal pain as a result of bariatric surgery. There are even instances wherein the Erector Spinae has been used to alleviate painful conditions of the shoulder girdle6. This report of a case of chronic pain associated with a disarticulated upper extremity aims to address the patient's long standing pain that was not totally relieved by specific nerve blocks corresponding to the body part involved and offer an alternative (erector spinae block ) that not only is comparably easier to master and administer but noticeably of faster onset in delivering relief of pain.

\section{METHOD AND RESULTS}

A 65 year old male, who had left extremity amputation near the shoulder joint secondary to a vehicular accident 14 years ago was referred to the pain management service because of chronic pain of the scapula and shoulder joint and the anterior chest near the axilla described as dull constant pain ranging from 5-9/10 pain score, aggravated by change in position, barely relieved by Tramadol with Paracetamol tablet as needed for pain, Pregabalin 75 mgs every 12 hours ( former physician suggested an impression of "phantom limb pain "). The patient had difficulty sleeping thus prompting consult. Initial physical assessment revealed trigger points at the pectoral area near the axilla and suprascapular area. Requesting immediate intervention, a suprascapular nerve block was done under ultrasound guidance using (Sonosite M-Turbo, Sonosite Inc Bothell, Washington, USA) linear high frequency probe, with $0.25 \%$ . shoulder joint and 40 mul with a total volume pain score of $0-2 / 10$ resting and with movement, with take home medications of Oxycodone $\mathrm{HCl}$ (Oxynorm) and Pregabalin 75 mgs BID continued.

A week after, the non-compliance with the opioid prompted return of the pain. Another consult was setup wherein this time, pain was noted relieved at the shoulder joint area but with the same intensity as before in the anterior chest and scapular area, a suggestion of doing an erector spinae block under ultrasound guidance was given. Seeing the convenience of the procedure in the clinic setting with minimal complications involved, the patient agreed. The patient was then hooked to monitors and was placed in a sitting position. Sonosite Edge with a high-frequency linear-array transducer was used to identify the T5 transverse process by high frequency linear counting down fom the (T). A longtudinal parasagittal identifying the transverse process of T5. An 8-cm 22G block needle (BBraun Stimuplex 360) was inserted in-plane directed towards the caudal direction positioning the needle tip between the posterior fascia of the erector spinae muscle and the T5 transverse process. Hydrodissection with normal saline was done and confirmation with fluid lifting the erector spinae muscle away from the transverse process observed, topping up with $30 \mathrm{~mL}$ of $0.25 \% \mathrm{~L}$ bupivacaine with $1 \%$ Lidocaine was injected. The patient noted immediate relief of pain within 10 minutes after the injection and exhibited no limitation in motor movement. The numbness was noted concentrating on the anterior chest more on the lateral aspect. He was discharged with the same prescription home medications and was advised follow up after two weeks with re same intensity, there was the possibility of catheter delivered continuous erector spinae blockade.
There was a return call after 1 week whereby patient was again non-compliant with the pain medications and the significant return of pain on the anterior lateral chest near the stump.After informed consent and application of standard monitoring, the block was carried out at the T5 level, with same settings for the Ultrasound. The patient was in a lateral decubitus position with the probe oriented in the parasagittal plane. A bolus of $20 \mathrm{ml}$ of $0.25 \%$ Levobupivacaine given after which a peripheral nerve block catheter (BBraun Contiplex) was then positioned, and a further $5 \mathrm{ml}$ of $0.25 \%$ Levobupivacaine was injected via the catheter under ultrasound guidance, with catheter tip confirmation. The catheter was secured in place.Patient was observed for an hour and was discharged after the continuous infusion of $10 \mathrm{ml}$ per hour $0.125 \%$ L-Bupivacaine was started using an fixed pressure elastomeric pump (Easypump by BBraun), and was continued for four days with take home medications of Morphine Sulfate $10 \mathrm{mgs}$ per tablet BID. The patient phoned in after 4 days expressing relief with a manageable score of an occasional 2- pain score. He was advised follow-up after a month for re-assessment.

\section{CONCLUSION:}

The erector spinae continuous infusion block has opened a lot of possibilities for answering calls to alternative pain interventions that are easy to master and yet is not compromising safety and quality of the pain relief achieved. As it was noted in this case report, even onset fo pain relief was more than ideal. Perhaps, a lot more still can be gained through discovery of the widening array of interventions to cure pain by the Erector Spinae Block.

References:

1. Mauricio Forero, MD, FIPP, ${ }^{\star}$ Sanjib D. Adhikary, MD, Hector Lopez, MD, Calvin Tsui, BMSc, and Ki Jinn Chin, MBBS (Hons), MMed, FRCPCIl The Erector Spinae Plane Block A Nove Analgesic Technique in Thoracic Neuropathic Pain Reg Anesth Pain Med 2016;41: 00-00

2. Hamilton, D.L., Manickam,B. Erector spinae plane block for pain relief in rib fracture BJA: British Journal of Anaesthesia, Volume 118, Issue 3, 1 March 2017, Pages 474-475

3. H. Ueshima and H. Otake, "Erector spinae plane block provides effective pain management during pneumothorax surgery," Journal of Clinical Anesthesia, vol. 40, p. 74, 2017

4. D. Bonvicini, L. Tagliapietra, A. Giacomazzi, and E. Pizzirani, "Bilateral ultrasound-guided erector spinae plane blocks in breast cancer and reconstruction surgery," Journal of Clinical Anesthesia, vol. 44, pp. 3-4, 2018

5. K. J. Chin, S. Adhikary, N. Sarwani, and M. Forero, "The analgesic efficacy of pre-operative bilateral erector spinae plane (ESP) blocks in patients having ventral hernia repair," Anaesthesia, vol. 72, no. 4, pp. 452-460, 2017

6. Mauricio Forero, MD, FIPP. Manikandan Rajarathinam, MD, FIPP. Sanjib Das Adhikary, $M D$. Ki Jinn Chin, MBBS (Hons), MMed, FRCPC Erector spinae plane block for the management of chronic shoulder pain: a case report Can J Anesth/J Can Anesth (2018) 65:288-293

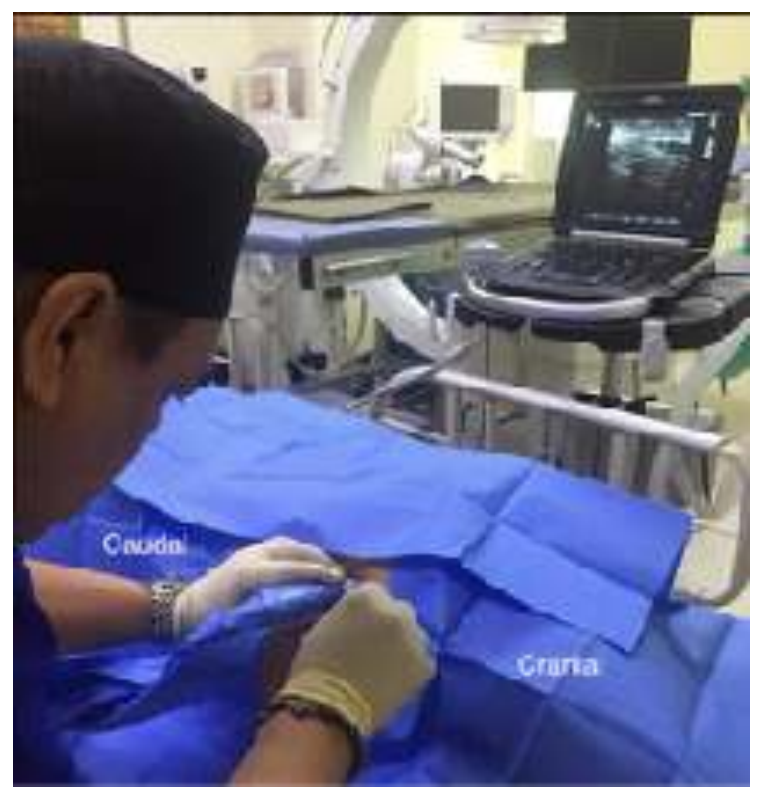

Patient in lateral decubitus position during the ES Block

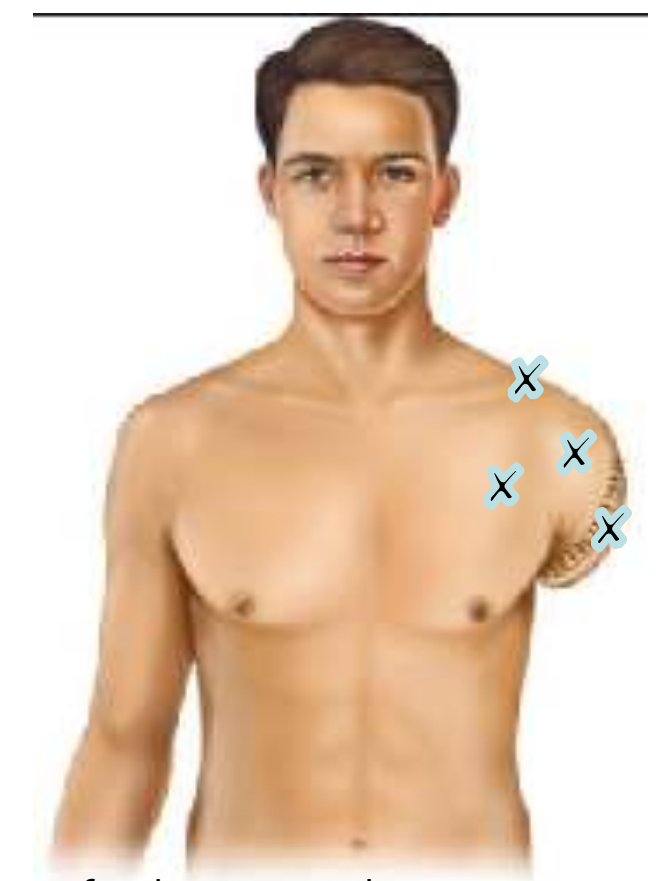

Specified points where patient was relieved after the block

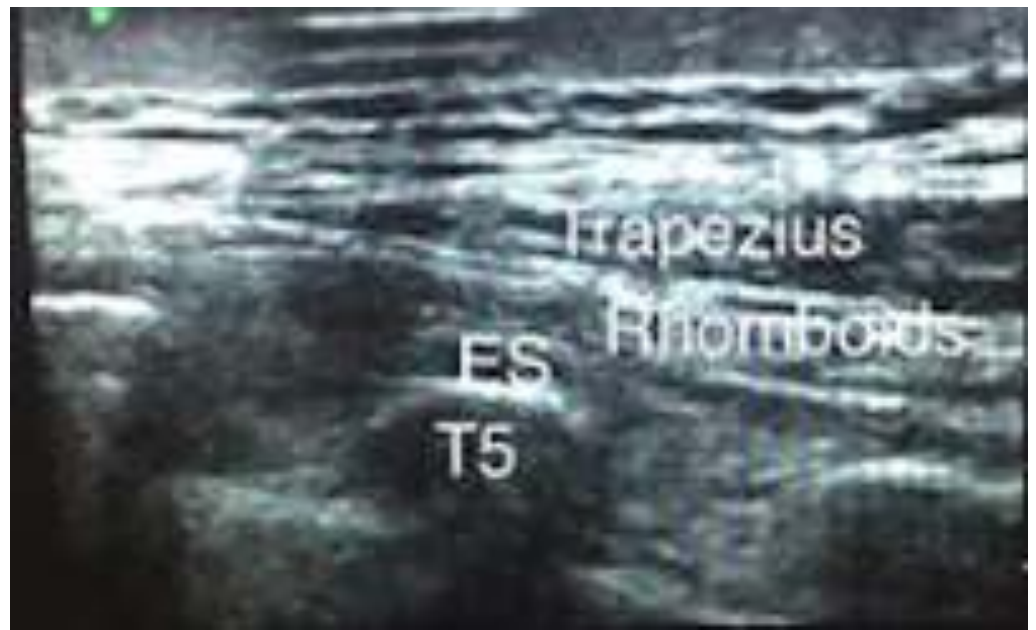

Ultrasound localisation of T5 level with Erector Spinae Muscle, Trapezius, Rhomboids 